\title{
Perspectivas históricas del nuevo orden económico internacional*
}

Existen varios modos de pensar acerca del "nuevo orden económico internacional". Por ejemplo, sería muy racional considerar que no hay factor tan nuevo, ni importante en la economía mundial como nuestra percepción repentina, en los años 70 , de que pođira haber límites a los suministros mundiales de materias primas, umbrales para la canticlad de contaminación que puede soportar el ecosistema planetario e interdependencias físicas completamente imprevistas $-\mathrm{de}$ suelo, de agua, de vientos y de climas-- las cuales, insospechadas hace todavia un decenio, podrian causar un daño permanente planetario, que afectaría tanto a Ias naciones ricas como a las pobres. Pero de hecho la frase un "nuevo orden económico internacional" significa hoy algo mucho más político, específico y preciso. Sus raíces se hallan en la aspiración fundamental de las naciones menos desarrolladas de que el final político de la colonización fuera seguido de una emancipación económica y social.

La idea es clara, pero dada la interconexión de los intereses económicos muncliales, la complejidad de los miles y miles de transacciones del comercio planetario, y, sobre todo, el grado de dependencia económica que se acumuló durante los años coloniales, la tarea se está revelando más complicada que la terminación política del imperio. Con unas pocas trágicas excepciones, el entero proceso - celebración del primer Día oficial de la Independencia, ceremonia de arriar bandera, firma de la nueva Constitución y ocupación del escaño correspondiente en las Naciones Unidas- ha resultado bastante fácil si se compara con el intento de tejer y destejer las estructuras creadas en varios siglos de profundizar las relaciones comerciales en el mercado mundial.

Oficialmente, la idea puede decirse que nació en mayo de 1974 en el Sexto Período Extraordinario de Sesiones de la Asamblea General de las Naciones Unidas. Una larga resolución, aprobada por consenso - pero, significativamente, con grandes reservas por parte de los EE. UU., Reino Unido, Japón y Alemania Occidental- estableció algunos principios básicos: 1) que las naciones deben gozar de la soberania sobre sus propios recursos, incluido el derecho de nacio-

* Preparado para la Mesa Redonda Norte Sur organizada por la SID en Roma, entre el 18 y el 20 de cnero de 1978, y publicada en Estudios Internacionales por autorización de la Sociedad Internacional para cl Desarrollo. 
nalizarlos; 2) que estos recursos deben aprovecharse mediante procesos de industrialización y la adaptación o invención de tecnologías apropiadas bajo control local; 3) que el clesarrollo del comercio mundial no debe ni interponer obstáculos particulares en el acceso de las naciones a otros mercados nacionales, ni actuar contra un equilibrio más equitativo entre el aumento de los ingresos de exportalción de los productos manufacturados por una parte y el descenso de los precios de la mayoría de materias primas y productos semielaborados por la otra; y 4) que los estados ya industrializados, y por ende ricos, deben poner a disposición de las naciones pobres más fondos en condiciones de favor.

Es quizás significativo que nada se haya dicho sobre la necesidad de operar cambios institucionales en los países menos desarrollaclos para hacerles más capaces de beneficiarse de los cambios a nivel internacional. Es evidente que ninguna cantidad de asistencia o comercio transformará una economía feudal, con el $90 \%$ de la tierra en manos de un $10 \%$ de habitantes, ni modernizar una dictadura militar inclinada a gastar hasta el último centavo de que dispone en armas o prestigio. Pero la Asamblea General es un foro internacional e insistir en las reformas interiores no es su función especifíca.

Donde las naciones reunidas descendieron a mayores detalles fue en la necesaria reordenación del comercio internacional. Se hizo referencia a la necesidad de algún tipo de fondo especial para apun. talar la financiación de reservas de estabilización a fin de consolidar los precios de una serie de productos básicos vuInerables - café, azúcar, té, sisal, y algunos minerales. Se sacó a colación también el tema de las finanzas de compensación para contrarrestar las caídas repentinas de Ios ingresos de exportación. Se suscitó la cuestión de sí no se podía someter a algún tipo de "indización" a las exportaciones primarias de las naciones pobres, para que sus precios aumenten automáticamente si las manufacturas importadas por los países industrializados continúan mostrando un movimiento inflacionario ascendente. Tal fue, en líneas generales, Ia primera declaración del nuevo orden económico. Pero, naturalmente, sus antecedentes se remontan a muchos años y algunas de las consecuencias que se desprenden son muy vívidas. Ambos aspectos deben examinarse si se quiere comprender su significado completo.

Antecedentes, histónicos. $\mathrm{E} 1$ punto de arranque es el mismo final del siglo $x y$ y. la flota de barquichuelos de audaces mercaderes que zaxparon de Europa Occidental para traficar con todas las mercazcías y lujos del Oriente. Entre los siglos xwr y xix, estos hombres y șus sucesores establecieron un mercado mundial. No estaban interesados especialmente en fundar imperios. Simplemente querían traficar. Observaron todas: las normas restrictivas al comercio impuestas 
por el Gran Mogol, emperador Akbar y sus sucesores en la India hasta que la dinastía fue derribada como consecuencia de guerras y rivalidades locales. Aún en el decenio de 1820, el comercio británico con la China estaba limitado a Cantón y a los mercaderes británicos no se les permitía ni siquiera los viajes fluviales. La experiencia era clara. Donde prevalecía una fuerte autoridad local, los europeos no tenían más remedio - ni quizás voluntad- que seguir siendo mercaderes. In el caso de algunos, sus gobiernos ni siquiera estaban seguros de querer comerciar. Es irónico recordar que en la Inglaterra de mediados del siglo xviri, cuando los temores por la balanza de pagos inquietaban al gobiemo, se levantó un clamor semioficial contra la costumbre de las nuevas clases medias de comprar tejidos extranjeros (damascos de Damasco, calicó de Calicut, muselina de la Bengala Musulmana) endeudando así a la Gran Bretaña con gobiernos extranjeros.

Pero allí donde la autoridad local era débil, desorganizada o tribal, Ios mercaderes se instalaban. Sus razones eran tan diversas que demuestran lo poco que las ocupaciones fueron actos de imperialismo institucional. Algunos deseaban proteger su comercio contra el desorden local, a otros les movía únicamente el ánimo de lucro. Algunas veces, las ambiciones genuinamente imperialistas de un procónsul local, un Clive o un Wellesley, desempeñaron un papel esencial. Pero, sobre todo, los ingleses, los franceses, los holandeses, los españoles y los portugueses se pasaban el tiempo conspirando, azuzando, las rivalidades locales y, finalmente, ocupando tierras para impedir que lo hicieran los demás. El resultado de cuatro siglos de confusas resistencias locales, colapsos, restauraciones e intervenciones ha sido un sistema mundial controlado por Europa, bien por asentamiento como en América o bien por dominación colonial como en casi todas las demás partes. En general, el sistema se mantuvo casi intacto nada menos que hasta 194.5, y uno de los propósitos fundamentales de sus gobernantes era el de comerciar e invertir en un mercado mundial con las menores injerencias posibles.

Llegados a este punto es necesario considerar una o dos características básicas de un mercado, no solamente del mercado mundial, sino de cualquier mercado. A pesar de sus grandes ventajas como medio descentralizado, objetivo y no regimentado de suministrar la variedad infinita de productos y servicios que la gente desea normalmente, tiene ciertas características que afectan a su utilidad y aceptabilidad tanto local como universal. Todo mercado viene condicionado en gran medida por el poder. Los primeros teorizadores del mercado -Adam Smith, David Ricardo- asumieron en general una igualdad aproximada en el trato entre compradores y vendedores. En este caso, el mercado es realmente un instrumento indispensable. ¿Pero supongamos que el poder está completamente dese- 
quilibrado? A comienzos del siglo xIx las masas obreras no tenían nada que ofrecer, excepto su trabajo. No podían negociar en absoluto y en virtud de lo que se llamó "la ley de hierro de los salarios" su recompensa por el trabajo apenas igualaba el mero costo básico de su supervivencia. Este nivel de "recompensa", como indicaron Engels y Marx, a duras penas podía proporcionar poder adquisitivo suficiente para la productividad y la producción creciente de las nuevas máquinas. Por ello, decían, el sistema se desplomará bajo las crisis de "superproducción", que en realidad cran de infraconsumo.

Sin embargo, a finales del siglo xix, la escasez de obreros en Norteamérica, la mejoría en la cualificación y de la enseñanza de los trabajadores en Europa Occidental, la acción de los reformadores, los comienzos del sindicalismo con la contratación colectiva y, sobre todo, el sufragio universal operaron un cambio en las relaciones de poder en los mercados industrializados. Luego, después de la segunda guerra mundial, la idea keynesiana de que el mantenimiento de la demanda efectiva -en otras palabras, el consumo- sería la clave del crecimiento económico contribuyó a 25 años de auge. Es cierto que en los años 70 la cuestión de si este poder de consumo siempre en aumento, alimentado por los elevados sueldos de las empresas y por el refuerzo de los sindicatos, pudiera sobrepasar la capacidad económica de satisfacerlo sin inflación, contribuyó decisivamente a la reacción del mundo desarrollado a las fluctuaciones del mercado, nacional o extranjero. Pero el punto importante aquí es subrayar el elemento de poder en la determinación del funcionamiento general de todo tipo de mercado.

Un hombre que pueda monopolizar o controlar el mercado de un cierto recurso esencial tiene un poder virtualmente absoluto, al menos por algún tiempo. Las naciones árabes con sus vastas reservas petroleras y sus reducidas poblaciones están en esta posición. Lo mismo ocurre en Norteamérica con su monopolio de los excedentes de cereales. Australia, Norteamérica y Sudáfrica no están muy lejos de detentar el monopolio del uranio. Por otra parte, las naciones de clara superioridad militar pueden monopolizar el mercado. Se suele decir, por ejemplo, que las raíces de la debilidad de las naciones menos desarrolladas en el comercio estriban en su forzada concentración de las materias primas. Pero la Unión Soviética puede fijar los precios de sus exportaciones de materias primas a Europa Oriental y comprarles a cambio sus productos industriales ventajosamente. Y, la historia nos enseña que uno de los medios más efectivos de lograr un gran poderío, e incluso un poder absoluto, es simplemente el control colonial. A lo largo de sus cuatro siglos de existencia, el mercado mundial ha estado, en términos generales, sujeto al poder y al control de los pueblos de Europa y posteriormente de sus descendientes, los colonos de los Estados Unidos. 
La economia de la vaca lechera. Este control colonial fue, en parte, causado y reforzado por otro factor, la Revolución Industrial. A partir de 1750 aproximadamente, primero la Gran Bretaña, luego Europa Occidental y el litoral del norte de América evolucionaron hacia tipos totalmente nuevos de producción en masa de productos para satisfacer las necesidades diarias de la gente y de producción de maquinaria para elaborar estos productos. Los productores artesanales locales quedaron así an:quilados y tuvieron que irse a trabajar a las fábricas junto a los trabajadores desposetdos y sin tierra. Pero en sitios como en Bengala, los tejidos nuevos de Lancashire acabaron con las hilanderas y los tejeclores que no tuvieron a dóncle ir. Las muselinas venian ahora de Manchester y' no de Dacca. A medida que avanzaba el siglo $\mathrm{xrx}$, los viejos sistemas comerciales se invirticron. Los europeos dejaron de buscar las manufacturas asiáticas. Explotaron minas y establecieron plantaciones para suministrar a sus propias fábricas las materias básicas. Africa, en parte por inversión clirecta, en parte por el odioso tráfico de esclavens, se había visto envuelta en el sistema desde hace tiempo, ya que la mano de obra esclava contribujó a producir algodón y azúcar en gran parte del Nuevo Mundo. Las pequeñas élites de señores feudales en America Latina se sumaron también al comercio, vendiendo azúcar, café, cereales y carne a cambio de productos industriales occidentales. Sin que lo planificara nadie en particular se estableció un mercado munclial en que el poder de las naciones recién industrializadas fue el factor determinante -aunque se le llamó "ventaja-relativa". Los gobernantes coloniales, las empresas industriales desarrolladas y los dirigentes locales tradicionales controlaban un sistema, por el cual las materias primas iban del "Sur" - América Latina, Africa negra y Asiaal Atlántico Norte, donde se transformaban en productos manufacturados y se vendían en los mercados locales, volviendo así a los productores primarios.

In el proceso, todos los scrvicios - transportc, banca, seguros, investigación de nuevos productos- permanecieron en manos de las potencias atlánticas. Todo el "valor añadido" procedente, digamos, de convertir un grano de cacao en un clulce de chocolate iba a revertir igualmente a los paises industrializados. Aun en los años 70 , las exportaciones de las 12 materias primas més importantes (sin contar el petróleo) de las naciones más pobres produjeron $30.000 \mathrm{mi}$ llones de dólares al año a los productores, pero costaron $200.000 \mathrm{mi}$ llones a los compradores antes de llegar al consumidor final. El saldo de 170.000 millones representa el "valor añadiclo" total del proceso industrial, casi enteramente absorbido por las naciones industrializadas.

El dominicano Père Lebret, distinguido economista, tiene una palabra para definir este intercambio mundial básico. Le llama l'éco- 
nomie de traite ("la economía de la vaca lechera"), consistente en ordeñar todo del "Sur" y enviarlo al "Norte", devolviendo lo justo para que funcione el sistema. Todos los servicios locales, todos los medios de comunicación, todos los sectores desarrollados del Sur sirven a este modelo. Las carreteras y ferrocarriles van a la costa. Prácticamente todas las grandes ciudades - de Shanghai a Valparaísoeran puertos de mar y servían de centros de depósito para un sistema esencialmente exterior. Las ciudades costeras de América Latina dieron al continente un grado más alto de urbanización a comienzos del siglo $\mathrm{xx}-\sin$ ni siquiera el $5 \%$ de la población en la industriaque Europa Occidental con al menos un $20 \%$ de mano de obra fabril. Así creció un urbanismo subordinado, vinculado no al interior del país, sino al sistema exterior atlántico. Este, dicho sea de paso, es el origen de las inmensas y desequilibradas metrópolis actuales del mundo subdesarrollado.

Secuelas de la colonización. Estos son, en términos generales, los antecedentes económicos, en parte todavía desconocidos e incomprendidos, del mundo que surgió en 1945. Las naciones industrializadas, compuestas de economías mixtas y planificadas, con cerca del $35 \%$ de la población mundial, tienen del 75 al $80 \%$ de la riqueza mundial, el $85 \%$ del comercio, el $90 \%$ de los servicios, más del $90 \%$ de la industria y casi el $100 \%$ de la investigación -porcentajes que se han mantenido virtualmente inalterados (salvo el porcentaje de la población mundial que reside en las naciones ricas que ha disminuido). El $70 \%$ de la población mundial que vive en el mundo menos desarrollado, o "Sur", como se le ha llamado, ha adolecido -y sigue adolcciendo- de los porcentajes opuestos correspondientes y, por lo tanto, de la falta de poder. Existe un mercado mundial, pero está completamente orientado hacia las necesidades de los gigantes industriales. Después de 1945 había que preguntarse no si un tal sistema podía perdurar, sino más bien cuán pronto sus iniquidades $\mathrm{c}$ inestabilidades empezarían a dejarse sentir en el ruedo político.

Los años 50 y 60 registraron algunos cambios preliminares de vital importancia. El primero fue la terminación del control colonial directo por las economías de mercado del Occidente y el establecimiento, finalmente, a través de las Naciones Unidas y sus organismos, del concepto de un sistema de cooperación a escala mundial que trascienda las relaciones de poder y los intereses puramente económicos. El segundo fue una aceptación modesta por las sociedades de mercado desarrolladas (los estados del bloque socialista desempeñaron un papel muy reducido a este respecto) del hecho de que los métodos comerciales ordinarios no bastaban para asegurar el crecimiento mundial. Era menester la prestación de asistencia y los créditos en condiciones de favor -el equivalente de la filantropía del 
siglo xix-para dar un impulso adicional a las nuevas naciones, con miras a desarrollar sus propias bases productivas y siguiendo las "ctapas de crecimiento" tradicionales, alcanzar, finalmente, el estado feliz de la sociedad de consumo industrializada. El tercer cambio fue el crecimiento fenomenal de grandes empresas multinacionales, con sede principalmente en América del Norte (con unas pocas en Europa). Sus dirigentes se sentían bastante capaces de guiar el comercio mundial sin el respaldo del control colonial y, lo que es más, se veían a sí mismos - a pesar de lo inapropiado de sus tecnologías de empleo intensivo de capital en economias ricas en mano de obra- como los principales instrumentos de modernización de los mercados del "Sur". Se les incitó a menudo con todo tipo de concesiones a introducirse en esos mercados, normalmente para apresurar por todos los medios posibles la industrialización local, la Cenicienta cle los tiempos coloniales.

La cuarta novedad fue la sensación molesta, que comenzó a percibirse ya a mediados de los años 50, de que esta combinación de un final oficial de la colonización politica, junto con la rápida expansión inclustrial local de matriz occidental (y normalmente de propiedad occidental también), podía de hecho dejar intactas las viejas relaciones de dependencia. En teoria, el mundo era libre. En realidad, el modelo de su economía seguía siendo colonial. Este fuc el malestar fundamental que comenzó a expresarse en una serie de conferencias del Tercer Munclo. La Conferencia Afroasiática de Banclung, Indonesia, fue la primera. Luego vino la serie de Conferencias de "los países no alineados" -Belgrado en 1961, El Cairo en 1964, Lusaka en 1970, Argel en 1973 y Colombo en 1976. Al mismo tiempo, las naciones menos desarrolladas empezaron a preguntarse si el papel fundamental que habían heredado de suministradores de materias primas cambiaría mucho en virtud de la labor de las nuevas organizaciones internacionales tales como el GATT (Acucrclo General sobre Aranceles Aduaneros y Comercio) o el FMI (Fondo Monetario Internacional). Se dieron cuenta que más del $80 \%$ de su comercio era todavía de producción primaria. Contaban escasamente con el $7 \%$ de la industria mundial y a pesar de que los decenios del 50 y del 60 fueron años de crecimiento rápido e incluso sin precedentes --el promedio de la tasa de crecimiento anual fue del orden del $5 \%$ - no parecian haberse movido de los escalones más bajos de una escalera mecánica, ya que por más que subieran, los ricos iban siempre por delante. Persistía la vieja dependencia. Es más, se veía reforzada por las nuevas deudas contraídas por la modernización. Movidos por estas preocupaciones, persuadieron al "Norte" a unirse a ellos para crear una nueva organización comercial, la UNCTAd (Conferencia de las Naciones Unidas sobre Comercio y Desarrollo), a fin de dar más peso a sus decisiones y poner más de relieve sus dificul- 
tades. Luego, en el Período de Sesiones de 1964 de la unctad, establecieron el Grupo de los 77 paises tercermundistas (que en 1977 contaba con 114 miembros) con objeto de que fuera un instrumento de mayor influencia - en otras palabras, de poder- en las negociaciones comerciales mundiales.

El arma del petróleo. Tal era la situación en 1973. Los estados del Norte tenían la sensación de haberse comportado de manera razonablemente abierta y generosa, abandonando el control colonial, transfiriendo cerca de 12.000 millones al año de asistencia, concediendo algunas oportunidades al comercio del Tercer Mundo mediante una lista cuidadosamente establecida de Preferencias Generales y participando en debates interminables con sus colegas del Sur, todas con la finalidad de allanar dificultades y enmendar agravios. Pero todas estas medidas positivas no parecían tener mucho peso al lado del bloque masivo de las relaciones inalteradas de poder y riqueza. Sólo unos pocos países en desarrollo - Corea del Sur, Taiwán y Brasil- habían reducido su dependencia de las exportaciones primarias. Fue en este escenario de inferioridad de condiciones profundamente sentida, donde la decisión de la opep (Organización de Países Exportadores de Petróleo) de quintuplicar los precios del petróleo en 1973 tuvo su efecto revolucionario.

Las repercusiones no fueron ni sencillas ni uniformes. Es más, para los países no productores de petróleo, tales como los del subcontinente indio, el aumento de los costos de los combustibles y los fertilizantes fue catastrófico. Para algunos otros - los estados densamente poblados productores de petróleo como Nigeria o Indonesia, por ejemplo- el aumento fue más que nada un paliativo para sus insuperables dificultades económicas. La sensación mayor se experimentó en el Norte. Francia, Alemania Occidental y Japón eran muy dependientes de las importaciones de petróleo. Las reservas norteamericanas estaban disminuyendo. Sobre todo, después de 25 años de "jolgorio", utilizando cada vez más petróleo a menos de 2 dólares el barril (hasta el 15\% al año en Japón, por ejemplo), las economías de mercado desarrolladas se encontraron repentinamente compartiendo algunas de las características de la posición tradicional meridional, no tener el control de una de sus decisiones económicas más cruciales. "El nuevo orden económico" pasó a ser visto en general -como, para el Sur, lo había sido siempre- como una cuestión de cambio del equilibrio de poder del mercado, el poder sin el cual las negociaciones económicas tienden siempre a favorecer a los más fuertes.

La nueva fuerza de la OPEP fue suficiente para entablar en muy poco tiempo negociaciones nuevas y más serias entre el Norte y el Sur sobre los mejores medios de regular sus relaciones económicas 
recíprocas. Una vez más, los paises de economías planificadas permanecieron prácticamente al margen. Los dos foros principales de negociación han siclo la UNCTAD y la Conferencia sobre Cooperación Económica Internacional (la denominada Conferencia Norte-Sur) de París, un grupo especializado de 27 naciones -8 del Norte y 19 (incluyendo 8 miembros de la OPEP) del Sur. En el orden del clía de ambos grupos figuraban los puntos principales de la resolución del Sexto Período Extraordinario de Sesiones de la Asamblea General de las Naciones Unidas.

Hay que admitir ante todo que, después de dos años de conversaciones, no se han logrado muclios progresos. La razón radica en los mismos trastornos y desórdenes de la economía mundial. Lil alza de precios de la OPEP coincidió con una expansión casi universal de las naciones industrializadas y con una cosecha tan catastrófica en la Unión Soviétrcá, que de hecho la URss compró, sin aspavientos, la entera reserva de cereales de América del Norte en 1972-73. El resultado fue la triplicación de los precios alimentarios mundiales y los tres elementos juntos -expansión, combustibles (con fertilizantes) y alimentos- pusieron en movimiento una espiral inflacionaria, que ni siquiera duras mediclas de recesión pudieron frenar. El fenómeno de la "estagflación", de puestos de trabajo en descenso y precios en aumento, se prolongaba en el Norte, lo que dificilmente ofrecla las mejores condiciones para un estudio sereno de las principales demandas del Sur.

Transferir más asistencia en condiciones de favor al Sur cuando la tasa interior de paro supera el $6-7 \%$ (y entre los trabajadores jóvenes el $25 \%$ ) se consideró políticamente imposible en el Norte desde el punto de vista nacional. Conceder mayor acceso a los productos manufacturados del Tercer Mundo -por ejemplo, camisas y zapatos-, pondría fuera de combate a más industrias que emplean intensivamente mano de obra de los sectores parados. Vincular los precios de las materias primas a los costos de los productos manufacturados mediante un sistema de indización podría verse como un método de inflación institucionalizada. Incluso el concepto cle promover la estabilidad de los precios mediante un fondo común, comprando varias rescrvas de estabilización en tiempos de abundante oferta o baja demanda y liberándolas para compensar la escasez incipiente, se parece demasiado a la asistencia de favor para que pueda aceptarse fácilmente. En todo caso, cl Norte no podría estar seguro de que el producto básico, cuyo precio desearía ver estabilizado -el petróleo-, figurase jamás en el programa. Estos conflictos directos y ásperos de intereses no han causado por lo menos la rotura, pero la fórmula favorita de evitar el punto muerto ha sido aplazar constantemente las decisiones hasta la próxima reunión. 
Las perspectivas. Hay cuatro razones que permiten nutrir aún un cierto optimismo. La primera se basa en la experiencia moral. Los ricos han aprendido, en especial sometidos a presión, a ser más justos y comprensivos con los pobres. La economía mundial moderna tiene sus reformadores, como los tuvo ia Inglaterra victoriana. El modelo no se ha perdiclo.

La prueba radica en la segunda razón. Las potencias industriales ricas no se han mostraclo, en realidad, enteramente obstinadas en no abandonar sus posiciones de poder. Por ejemplo, en 1974 el FMI instituyó un "servicio especial" de 3.000 millones de dólares para ayudar a las naciones más pobres a sufragar sus nuevos gastos de carburantes y lo èlevó a 10.000 millones en 1977. En febrero de 1975, en Lomć, Togo, los miembros de la Comunidad Económica Europea se reunieron con un numeroso grupo de estados asociados de Africa, el Pacífico y el Caribe. Se concertaron algunos acuerdos importantes $-\mathrm{y}$ posiblemente ejemplares - sobre los problemas que más preocupan a las naciones menos desarrolladas. Se ha dispuesto el acceso en franquicia al mercado de la CEE sin ninguna concesión recíproca para la mayoría de los productos industriales y - con ciertas restricciones- para las exportaciones agrícolas de los paises más pobres. Se ha establecido un fondo de 450 millones de dólares (por cinco años) para compensar las fluctuaciones de precios de los productos primarios importantes -el llamado plan Stabex-. Además, se ha negociado una cifra cle ayuda general de 3.550.000.000 dólares, también para los próximos cinco años.

Esta sensación de una reacción algo mayor se manifestó de nuevo en el 79 Periodo Extraordinario de Sesiones de la Asamblea General, celebrado en 1975, donde, aunque sin acuerdos específicos, surgió una cierta disposición a reconocer las viejas quejas de discriminación comercial del Sur y a expresar ciertas señales de una nueva comprensión de que podría existir una interdep̣endencia genuina de intereses entre el Norte y el Sur.

$Y$ ésta es Ia tercera razón para sentir un optimismo moderado. Las negociaciones de la UNCTAD están aplazadas clesde 1976 y las conversaciones de París han concluido virtualmente, pero ha habido algunos progresos. Un nuevo organismo, la Comisión Brandt, se ocupará simultáneamente de los intereses conjuntos del Norte y del Sur y hay mayor predisposición a contemplar conjuntamente el orden mundial, precisamente porque el cambio de las relaciones de poder están poniendo en juego intereses anteriores del Norte y aquí es posible discernir un terreno común. La "estagflación" del Norte no puede interrumpirse sin que termine la presión sobre los precios. Igualmente, a corto plazo, a medida que desarrollan sus economías los estados del Sur necesitan un Norte que sea razonablemente próspero para proporcionar capital y mercados. La combinación de las presio- 
nes de los "subprivilegiados" y el interés ilustraclo de los afortunados, podria, como en la Inglaterra victoriana, empezar a surtir efectos.

La cuarta razón para el optimismo moderado radica, no en la presente fase de las negociaciones para el nuevo orden económico, sino en la más amplia experiencia de la economía mundial en el siglo xx. Fue el colapso, entre 1927 y 1929 , del poder adquisitivo de los productores primarios, que acabó con los agricultores de los $\mathrm{EE}$, UU., lo que desencadenó la crisis de 1929. Luego el proteccionismo creciente de las naciones industrializadas lo convirtió en la quiebra universal de 1931. No se hizo nada y empezó la deriva hacia la guerra. En 1947, una vez más, el poder adquisitivo estaba debilitado totalmente, esta vez en Europa y en todas sus colonias a

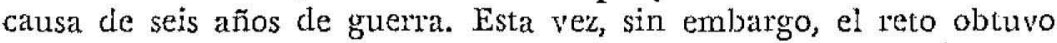
una respuesta notable. Los EE. UU., a un nivel de prosperidad de la mitad del actual, regalaron con el Plan Marshall un 2,5\% de su producto nacional bruto - diez veces el porcentaje presente de asistencia- - y en cuatro o cinco años hicieron recuperar a Europa y revivir al comercio del mundo entero. No hace falta tener la fe de? carbonero para esperar que a los estadistas del Norte se les ocurra que hay un lugar en que el poder adquisitivo es inexistente, pero cuyos recursos están esperando ser explotados y que se trata de la cuarta parte del mundo, que subsiste con un ingreso medio por habitante de poco más de 150 clólares al año. Un "Plan Marshall" de diez años, financiado por el Norte y la op:e, para desarrollar la agricultura y la industria del Sur, liberar a las masas de pobres consumidores, hacerlos productivos y darles trabajo fijo y remuneraciones justas, crearía nuevos recursos y mercados para el Norte y para el Sur y permitiría trocar la retórica de la interdependencia en alianzà genuina de intereses productivos.

En el siglo $\mathrm{xx}$ hemos conseguido fracasar y triunfar. Es dificil creer que con una tal experiencia histórica inmediata de altibajos, elijamos la senda del desastre. En la próxima reunión - cle París o de la UNCTAD- quizás empiece a tomar forma el auténtico "pacto global" del decenio de 1980. Quizás el mundo pueda pasar de la esperanzá y el sueño a la concreción de la realidad. Como dice una metáfora musulmana, no inadecuaca, podemos pasar de "las Puertas de Marfil a las Puertas de Asta". 